Conclusion Intervention helped to improve upon knowledge and change in attitude but one time intervention is not enough and sustained efforts are required to bring adequate and a positive change in the minds of youth to stop stigma and discrimination. Conflict of interest None.

\section{P03.09 IMPLEMENTING SEXUAL HEALTH 'SPACED EDUCATION' FOR UNDERGRADUATE MEDICAL STUDENTS IN NEW SOUTH WALES, AUSTRALIA}

${ }^{1} \mathrm{M}$ Bonner* ${ }^{*}{ }^{1} \mathrm{C}$ Bourne ${ }^{*},{ }^{2}$ J Rhee, ${ }^{3} \mathrm{~F}$ Robinson, ${ }^{2,4} \mathrm{M}$ Tam. ${ }^{1} \mathrm{NSW}$ STI Programs Unit (STIPU); ${ }^{2}$ University of NSW (UNSW); ${ }^{3}$ University of Sydney (USYD); ${ }^{4}$ Fairfield Hospital, Sydney

\subsection{6/sextrans-2015-052270.237}

Introduction Most STIs are managed in primary care settings in Australia, so the New South Wales (NSW) STI Programs Unit supports sexual health education of professionals in these settings. However each NSW undergraduate medical school curriculum is different and is inconsistently taught. To support some consistency in teaching, the Workforce Education Development Group (WEDG) University of Sydney (USyd) agreed to develop and implement a sexual health module for medical students using spaced education (Qstream). Spaced education has been shown to improve knowledge acquisition, increase long-term knowledge retention and change behaviour.

Methods The University of NSW and USyd Medical School Academic Departments of General Practice agreed to pilot the module during undergraduate primary care clinical attachments. Sixteen clinical scenarios with questions, model answers, references, and links to key resources were developed.

Results Forty two undergraduate medical students completed the pilot providing mostly positive feedback about the delivery method (interactive, daily reminders, retesting knowledge) and content (realistic clinical scenarios). The main criticism was the desire for more case studies to compliment or fill gaps in prior learning.

The sexual health module is now offered during $5^{\text {th }}$ and $6^{\text {th }}$ year Primary Care attachments at UNSW and is a required learning activity during $3^{\text {rd }}$ year Community Health block at USyd.

From August 2014-March 2015, 88 students from UNSW have commenced the course with a $50 \%$ completion rate. From October - December 2014, all 61 medical students at USyd completed the course with $64 \%$ finding the course very helpful or helpful. Feedback since module implementation remains positive with mobile friendliness, reminders, gradual learning and scenario rationales all rated highly.

Conclusion Spaced education has proven adaptable to sexual health education and was accepted as beneficial and a positive style of learning about sexual health. Other NSW undergraduate programs have now been offered the module.

Disclosure of interest statement The NSW STI Programs Unit is funded by NSW Health. No pharmaceutical grants were received in the development of this project.

\section{P03.10 WORKING TOGETHER- PRIMARY HEALTH CARE NURSES TAKING THE LEAD IN SEXUAL HEALTH CARE}

${ }^{1} \mathrm{M}$ Bonner, ${ }^{2} \mathrm{R}$ Rolleston, ${ }^{3} \mathrm{E}$ Wheeler. ${ }^{1} \mathrm{NSW}$ STI Programs Unit (STIPU); ${ }^{2}$ Roslyn Rolleston Education Services; ${ }^{3}$ Australasian Society for HIV Medicine (ASHM)

10.1136/sextrans-2015-052270.238
Introduction Primary health care nurses (PHCNs) frequently report being interested in sexual health care, believe sexual health care is important, see sexual health care as part of their role and want to further develop their skills in this field. However recent Australian studies demonstrate that opportunities for PHCNs in sexual health care in general practice appears to be underdeveloped and under supported.

Methods The Australasian Society for HIV Medicine (ASHM), NSW STI Programs Unit and Australian Primary Health Care Nurse Association (APNA) consulted PHCNs in NSW about their current role, interest in sexual health care and what they believed would assist to further develop their role in this field. Partnerships were formed between NSW primary health care organisations (Medicare Locals), public sexual health services, Family Planning NSW and training providers to also identify how to respond to the identified need.

Results Key strategies identified by PHCNs to enhance their role in sexual health care in general practice included the development of competency standards, provision of online training and strong support from GPs. A multi-pronged approach has been undertaken using competency standards and clinical tools to support education and practice, clinical placements in sexual health services to further develop skills and practical resources such as how to bill patients to support this change of practice.

Conclusion PHCN are interested in expanding their role in general practice and are in a pivotal position to lead significant changes in general practice for the provision of sexual health care to the community. Key elements to assist this include effective support from GPs, the provision of clinical tools and education and opportunities to connect with sexual health services. Finally primary health care nurses' own determination and perseverance to take a lead role in sexual health care is critical to the success of this practice change.

Disclosure of interest statement The NSW STI Programs Unit is funded by NSW Health. No pharmaceutical grants were received in the development of this project.

\section{P03.11 KNOWLEDGE ABOUT SEXUALLY TRANSMITTED INFECTIONS AMONG A NEW ZEALAND UNIVERSITY POPULATION}

${ }^{1} \mathrm{HJ}$ Denison*, ${ }^{1} \mathrm{~A}$ Jutel, ${ }^{1} \mathrm{H}$ Patel, ${ }^{1,2} \mathrm{EM}$ Dennison. ${ }^{1}$ Victoria University of Wellington, Wellington, New Zealand; ${ }^{2}$ Medical Research Council Lifecourse Epidemiology Unit, University of Southampton, Southampton, UK

\subsection{6/sextrans-2015-052270.239}

Background Sexually transmitted infection (STI) rates are known to be high in New Zealand, for example the incidence rate of Chlamydia is almost double that of Australia and the United Kingdom. If public awareness about STIs is low, including knowledge about transmission, risk factors, symptoms and treatment, this could be a contributing factor to the high rates observed. To date however, there has been very little assessment of STI knowledge in New Zealand. We addressed this in this pilot study.

Methods This analysis is part of a larger study assessing healthseeking behaviour for STI among students. A questionnairebased survey was used to obtain basic demographic information and STI knowledge information from students attending a university health centre in the North Island of New Zealand. Students could self-select to take part by picking up a copy of the questionnaire in the waiting room. Seven STI knowledge questions were used, each comprising a statement for which the 